\title{
International lab experts form Global Lab Experts Network
} gathered recently in Frankfurt, Germany, for an event organised by Dentsply Sirona, the world's largest manufacturer of professional dental products and technologies.
More than 50 international lab experts

Dentsply Sirona Lab says it is committed to offering the opportunity to establish a network with experts across all lab-related areas and enable the exchange between peers in every field of expertise.

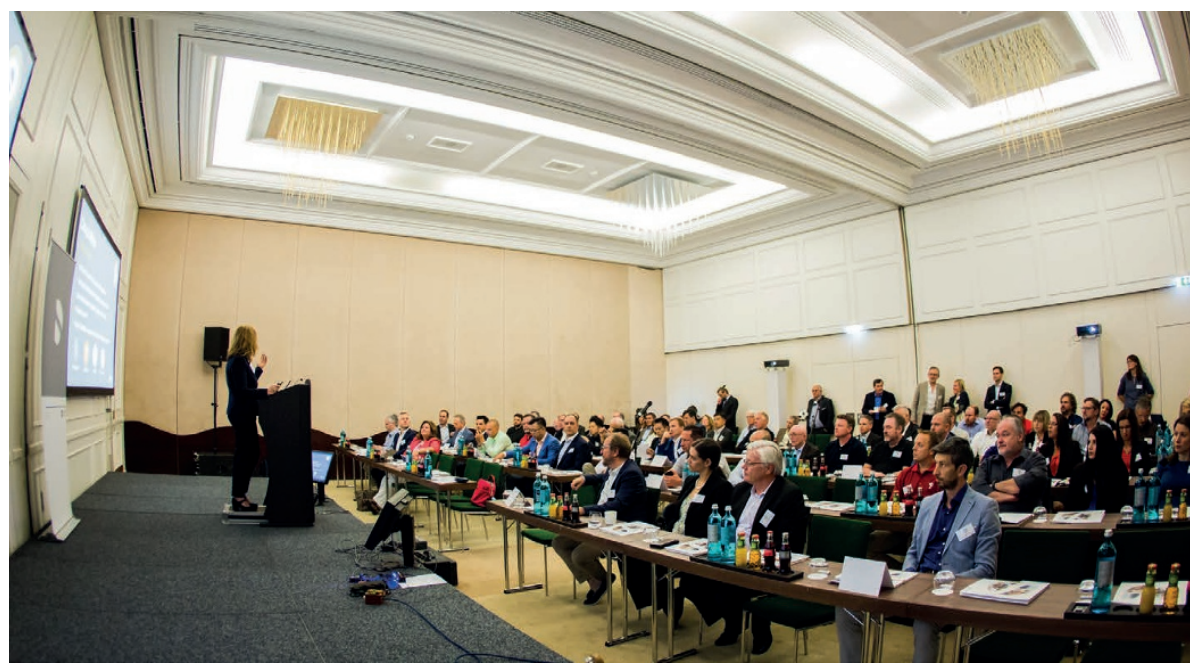

From 9 to 11 July 2018, Dentsply Sirona Lab, with its dedicated focus on dental technology, held its first ever Global Lab Experts Network (GLEN) meeting.

The meeting was intended to offer the possibility for networking and exchange between lab experts and around 50 key opinion leaders from almost 20 different countries came together for this peer-to-peer exchange to discuss current topics as well as future trends of dental technology and dentistry in workshops and interactive sessions.
Therefore, its Clinical Affairs team had initiated the Global Lab Experts Network and to kick off this programme, dental technicians, dentists and lab owners from all over the world had come to Germany.

The attendees from all five continents participated in a comprehensive two-day programme with varied general and breakout sessions and the possibility for a professional exchange with peers and colleagues. One main focus was also the importance of a successful teamwork between dental technician and dentist.
Tom Leonardi, Group Vice President at Dentsply Sirona Lab, said: 'Dentsply Sirona has the intention of organising this kind of GLEN meeting every two years, establishing a network of experts across all lab-related areas.

'The atmosphere at the premiere edition was great, bringing together industry experts from all over the world for the very first time. These types of meetings facilitate exactly the required regular update on products and techniques for lab experts.'

Attendees exclusively toured through Dentsply Sirona's Bensheim and Hanau production facilities, where participants were able to experience how the products for the labs are manufactured, from fixed traditional and CAD/CAM materials to equipment and technology.

After a welcome speech from Dentsply Sirona's Senior Vice President Technologies and Equipment Segment, Dominique Legros, the visitors were given a lecture by Dentsply Sirona's Chief Clinical Education Officer Dr Terri Dolan, who pointed out the importance of continuing education.

'We have built the broadest education platform in the industry, helping dental professionals get the knowledge, skills, inspiration and certification they need to stay up-to-date as well as develop themselves and their businesses,' said Legros.

More information about Dentsply Sirona and its products is available at www.dentsplysirona.com.

\section{Expert tips on periodontal diagnosis}

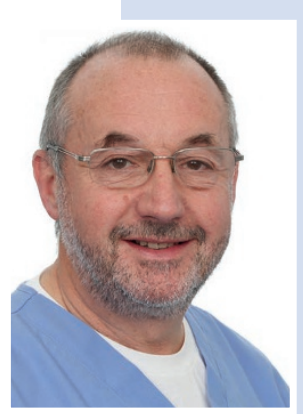

Attendees at a national conference will be treated to tips and advice on periodontal diagnosis during this year's Oral Health Conference and Exhibition (OHC) 2018 being held on 23 and 24 November 2018 at the Telford International Centre.

One of the speakers is Phil Ower, one of the UK's leading periodontists, who was the RAF's leading adviser in periodontology, managed the RAF School of Dental Hygiene, lectured at the renowned Eastman Dental Institute and served in several specialist dental practices. He was an examiner for the Royal College of
Surgeons of England (MGDS) for over a decade and has served two terms on the Council of the British Society of Periodontology (BSP), including serving as BSP President in 2016.

Ower will be giving a presentation entitled 'Perio classifications and diagnosis' at the conference on 24 November at $9.15 \mathrm{am}$.

Ower said: 'I will be discussing all aspects of periodontal diagnosis, from the need to do a full and detailed assessment of the patient to the use of the new classification system for periodontal and peri-implant diseases that was released during Europerio 9 in June 2018.

'Right now the biggest challenge is getting used to the new periodontal classification system, which is radically different from what we have been used to for the last 20 years.
I want to try and make the new system workable for those in general practice.'

Ower is a keen advocate of the $\mathrm{OHC}$ and added: 'The $\mathrm{OHC}$ is one of the most important dates in the postgraduate calendar, concentrating as it does on high quality science and state-of-the-art thinking in oral health. It is always a great way to network and catch up with old friends so I'm looking forward to it, especially as retirement looms!'

A 25\% early bird discount is available for those who book a place at the conference before 10 September 2018.

More information is available at www. bsdht.org.uk/OHC2018 or by calling 01788575050 or emailing to enquiries@ bsdht.org.uk. 